\section{Escrita e différance}

\section{Flávio Vinicius Cauduro}

Professor FAMECOS/ PUCRS

PhD em Comunicação Gráfica - University of Reading - UK
DE ACORDo com o filósofo Jacques Derrida, a escrita (ou 'arqueescrita') mental é a pré condição de qualquer significação. Ela não é tão somente ação, movimento, pensamento, reflexão, consciência, inconsciência, experiência, afeto, mas tudo isso emais ainda, diz ele. Para Derrida, escrita designa não apenas os gestos físicos literais implícitos em inscrições pictográficas ou ideográficas, mas também a totalidade daquilo que a torna possível:

“. . . chamamos de 'escrita' tudo aquilo quedáorigemàumainscrição em geral, seja ou não literal ou mesmo se aquilo que ela distribui no espaço é alheio à ordem da voz: cinematografia, coreografia, naturalmente, mas também a "escrita" pictórica, musical, escultural . ...É tambémnessesentido queo biólogo contemporâneo fala de escrita e programa em relação aos mais elementares processos deinformação na célula viva. $\mathrm{E}$, finalmente . . o campo total coberto pelo programa cibernético será o campo da escrita." (Derrida 1967/ 1976: 9)

Porque o queécomum à todas as práticas da significação éa possi bilidade do traço instituído existir antes de ser corporificado em um significante (Derrida 1967/ 1976: 46). Como observa N orris (1987), o argumento de Derrida podeser posto de manei ra mais simples nos seguintes termos: "Se a escrita é a condição maior do conhecimento - se, digamos, pudermos mostrar que ela precede e articula todas as nossas noções de ciência, história, tradição, etc. - então como pode a escritaser apenasumobjeto deconhecimento entre tantos outros?" (N orris 1987: 94).

O traço instituído, a grama que suporta a arque-escrita, sempre precedequal quer ato de comunicação, quaisquer marcas gráficas presentes em uma página: eles terão sempre sido já escritos em nossos cérebros, em nossa memória inconsciente, como argumenta 
Derridaem seu texto sobre "Freud eacena da escrita" (Derrida 1967/ 1978: 196-231). Em consequência disso, acentua ele, é “com uma grafemática ainda por vir, e não com uma lingüística dominada por um fonologismo antigo, que a psicanálise se vê destinada a colaborar" (Derrida 1967/ 1978: 220).

SegundoDerrida, otraço instituído pode parecer não-motivado, ou arbitrário, como Saussure e seus seguidores estruturalistas postularam, mas defato, acrescenta, não existe traço não-motivado, porqueo traço está sempre já motivado e está indefinidamente e re petidamente preso a um processo subjetivo de desmotivação, de objetificação racional: "Na linguagem saussureana, o que Saussure não diz teria que ser dito: não existe nem símbolo nem signo mas um tornar-se signo do símbolo [símbolo aqui tendo o sentido saussureano, inverso do de Peirce, de 'signo motivado']" (Derrida 1967/ 1976: 47, ênfase minha).

Derrida nota que isto já tinha sido apontado por Peirce (que chamava de 'símbolos' aquilo que Saussure chamava de 'signos'), que escreveu:

“... é apenas a partir de símbolos que um novo símbolo pode crescer. 0 mne symbolum de symbolo. Um símbolo, uma vez em existência, seespalha entre as pessoas. Através do uso e da experiência, seu sentido se amplia." (Peirce 1893/ 1940: 115)

Derrida nota que Peirce já se encaminhava na direção da desconstrução do significado transcendental, postulado pelo logocentrismo e pela metafísica da presença, ao propor sua famosa relação triádica representamen - objeto - interpretante para explicar a significação. Porque a assim chamada 'coisa-em-si-mesma', o objeto, o referente do signo-representamen, está inacessível à simplicidade da evidência intuitiva, já que esse objeto 'já é sempre um representamen' (Derrida 1967/ 1976: 49); isto é, o objeto representado já ésempre também um significante para o próximo signo associ- ado (o interpretante) na cadeia de significação. Só podemos pensar em signos, por meio designos, dizia Peirce - não há como conhecer a real idadediretamente("o real éo impossível", como diria maistardeLacan): todas as nossas experiências são mediadas, interpretadas por associações designificante, só interrompidas por eventos externos e imprevistos. Assim, representamen ou significante, objeto ou significado denotado, einterpretante ou significado(s) conotado(s) são em realidadeapenastrêsestágiosou posiçõestemporais e provisórias do signo na cadeia significante.

Portanto, o significado saussureano é apenas um momento na vida do signo, ao invés de um conceito transcendental unido para sempre ao significante: “ $A$ identidade própria do significado seescondeincessantementeeestásempreemmovimento" (Derrida 1967/ 1976: 49), ou seja, o significado "está sempre e já na posição do significante" (Derrida 1967/ 1976: 73). O significado, em outras palavras, é da mesma natureza e se encontra no mesmo plano do significante, o que desconstrói a noção estrutural ista deum signo formado em dois níveis espaciais, materiais distintos.

Coward \& Ellis(1977) por suavez, acrescentam que, com essa afirmação,

“Derrida indica a impossibilidade de um simples escape da metafísica: não é possível simplesmente rejeitar tais noções como 'conceito', 'significado', [conteúdo,] etc.: 'eles são necessários e presentemente pelo menos nada pode ser pensado sem eles'(D e la Grammatologie, p.25). A questão não é [simplesmente] refutar estasidéias mas sim como 'sacudir por completo' a tradição da qual fazem parte. O signo éo 'elemento central denossa cultura' eédevidoà primazia que Ihe é conferida nas teorias do sentido edalinguagemquetem possibilitado a repressão do materialismo. Contudo, por sua ambiguidade, o signo também abriu a possibilidade de afirmação do materialismo. Porquetãologo se questione a noção de 'significado', o 
próprio signo é problematizado, o que sugere que a linguagem é um movimento de significantes." (Coward \& Ellis 1977: 125, ênfase minha)

Na linguagem temos, portanto, apenas significantes e ela é, fundamentalmente, o processo material de associação temporal de tais significantes: éa significação, ou seja, dito do ponto de vista materialista, é a praxis discursiva, a prática significante.

Por sua vez, ao criticar a noção ideal ista Cartesiana do sujeito pensante consciente de si mesmo, unificado, racional, queestá implícita em teorias tradicionais do signo, Derrida propõe que pensemos a linguagem como se fosseum jogo baseado na ausência do significado transcendental, onde, desde o instante inicial, sejamos cúmplices do processo de 'tornar-se não-motivado' do signo (Derrida 1967/ 1976: 50). Nesse processo de transformação contínua, onde mudamos repetidamente nossa leitura do mundo das posições de leitura icônica eindicial para a simbólica, a oposição Saussureana entre diacronia e sincronia, ea noção desistema como estrutura estática não mais se sustentam, pois "a imotivação do traço [o rastro da trajetória significante na mente] deve agora ser entendido como uma operação e não como um estado, como um movimento ativo, como uma desmotivação, e não como uma dada estrutura" (Derrida 1967/ 1976: 51).

Por tudo isso, Derrida argumenta quea linguagem é fundamentalmente escrita, ou arque-escrita (archi-écriture), ou seja, uma escrita generalizada e constante que precede tanto a fala como a escrita gráfica própriamente dita: 'a escrita generalizada [a que me refiro] não é apenas a idéia de um sistema a ser inventado, uma característica hipotética ou uma possibilidade futura' (Derrida 1967/ 1976: 55), mas um processo material bem concreto mas reprimido pela tradição logocêntrica. Como el ecoloca, paradoxalmente:

“Eu gostaria de sugerir que a pretensa derivação da escrita, mesmo que real e massiva, sófoi possível baseadaemuma condição: que a linguagem 'original', 'natural', etc. nunca tivesse existido, nunca tivesse estado intacta e intocada pelaescrita, [istoé,] queela própriateria sido sempre uma escrita." (Derrida 1967/ 1976: 56, ênfase minha)

A arqueescrita de Derrida, baseada na noção da grama ou traço dinâmico, subentende portanto todas as inscrições que estão sendo continuamentemarcadasno cérebroeconstituem a escrita do pensamento. Sendo tanto estrutura como movimento, essa escrita explica:

- a différence (diferença entre), ou temporal ização e espaçamento, a não-identidade, a discernibilidade, a alteridade dos signos (Derrida 1972/ 1982: 8);

- easimultâneadifférance (termo inventado por Derrida, equival entea diferimento), queéum adiamento simultâneo, um retardamento, um cálculo econômico, uma divergência, uma demora, um prazo, uma reserva, em suma, uma temporização do signo em relação a outros, um desvio consciente ou inconsciente que suspende a obtenção e o completar do desejo na significação (Derrida 1972/ 1982: 8), fenômeno já postulado por Lacan, ao falar sobre o escorregamento metonímico contínuo do significado sob o significante, emseusseminários (Lacan 1966/ 1977; Jefferson 1986: 112-116).

Derrida utiliza o trocadilho différance para referir-se à essas duas características simultâneas da significação, poiselemostraa impossibilidade de diferenciar pela fala a palavra différence do novo termo différance, uma vez que os sufixos -ence e -ance tem exatamento o mesmo som no idioma francês, uma ambigüidade que não ocorre quando essas pal avras são escritas. Com esse jogo de letras ele também quer demonstrar como qual quer signo (nesse caso um escrito) evoca einvoca traços de outros signos na significação. N ovamente, isso já tinha sido postulado por Peirce através da noção de semiose, a significação recursiva, aregressão infinitadas relações entre signos possibilitadas pelo 
interpretante. Saussure, igualmente, jáobservara em seu Curso que cada signo era como que o centro de uma constelação de outros signosassociados, o quelevou posteriormente Lacan a figurar o signo como sendo um carr efour , uma encruzilhada, um nó, um ponto deencontro deoutros signos, na cadeia, ou rede, significante.

Norris (1987: 15), ao comentar a estratégiadesconstrucionistadeDerrida, sugereque suaintenção émostrar, com humor eoriginalidade, e através da própria escrita do seu conceito-chave différance, que o sentido é ao mesmo tempo 'diferencial' e 'diferido', produto de um jogo incessantedentro dalinguagem, jogo que não pode ser fixado ou paralisado quando se procura uma definição de conceito: "o sentido não está pontualmente presente em lugar algum na linguagem, ele estásempresujeito àuma espéciedederrapagem (ou demora) semântica que impossibilita o signo de jamais (por assim dizer) coincidir consigo mesmo em um momento deapreensão perfeita, sem resíduos" (Norris 1987: 15). Portanto, a différance, ela própria, assim como qualquer outro signo ou significante, "deveria funcionar não como um conceito, não como uma palavra cujo sentido pudesse ser finalmente 'registrado no presente', mas sim como um conjunto de marcas numa cadeia significantequeexcedee perturba a economia clássica dalinguagem eda representação" (Norris 1987: 15).

De fato, como escreve Derrida, na différance "o estranho movimento do traço proclama tanto quanto lembra: différance difere-diferencia" (Derrida 1967/ 1976: 66). "Na sua polissemia esta palavra, naturalmente, como qualquer sentido, deve diferir em relação ao discurso no qual ocorre, seu contexto interpretativo" (Derrida 1972/ 1982: 8, ênfase minha), o que explica porque “différance se presta para um certo número de substituições não-sinônimas [tais como reserva, arque-escrita, espaçamento, suplemento, pharmakon, etc.], deacordo com a necessidade do contexto" (Derrida 1972/ 1982: 12).

Como Saussure já tinha enfatizado, um signo é aquilo que outros signos não são, e tem apenas um valor social relativo, determinado por sua (o)posição em relação a outros signos do sistema. Selembrarmosqueo sujeito tambéméum signo, como postulou Peirce, é fácil de entender a proposição acima de Derrida e suas implicações. Contudo, a différance de Derrida não éa mesma diferença de Saussure, que se apoiava em oposições estáticas; o diferir introduz a noção de um efeito temporal, dinâmico. Como o próprio Derrida(1972/ 1982) nota, elecunhou otermo différance justamente para chamar atenção para esse fato, uma vez que

“... a diferença marcada na 'différ( )nce' entreo e eo a eludetanto a visão quanto à audição etal vez sugira com felicidade que aqui nós possamos ter a permissão denos referirmosà uma ordem quenão mais pertence à sensibilidade. Mas ela também não pode pertencer à inteligibilidade . . . . Aqui, portanto, devemos nos referir à uma ordem que resiste à oposição, uma das oposições fundadoras dafilosofia, entreo sensível eo inteligível." (Derrida 1972/ 1982: 5)

Richard Harland sugere que quando Derridachamanossaatençãoàintrinsicapossibilidade de todos os sentidos serem ambíguos, como na palavra 'pharmakon' (usada por Platão em Phaedrus para condenar a própriaescrita), queem grego podesignificar, paradoxalmente, tanto 'veneno' como a sua antítese 'remédio', eleestá enfatizando queo sentido de'veneno' não existemeramenteem virtude de sua diferença do sentido de 'remé dio', mas também em virtude de diferir em relação ao sentido de 'remédio': “E o sentido que é diferido é adiado apenas pelo presente; ele ainda paira, ele ainda espera, e no justo tempo o sentido que difere terá que desaguar nele [i.é., no sentido de remédio]" (Harland 1987: 138). A linguagem, de acordo com Derrida, é portanto um jogo sistemático de diferenças, uma 'escrita' detraços dediferenças, um espaçamento, pelo qual os seus elementos palpáveis, os significantes, entram 
em constante relacionamento dinâmico uns com os outros (Coward \& Ellis 1977: 126).

Para fundamentar melhor sua tese, Derrida argumenta - endossando a conhecida proposição de Lacan que 'o inconsciente é estruturado como uma linguagem' (Lacan 1973/ 1979: 20), como uma linguagem de significantes sem significados (Lacan 1972: 316) - que processos inconscientes participamdasignificação equeoinconscienteexiste na forma de sua 'arque-escrita', como um texto ou escritahieroglíficagravadanamatéria cerebral, que não só precede a fala ea escrita gráfica, como também é o fundamento de todo nosso pensar e agir. Harland (1987) observa que:

\begin{abstract}
“ParaDerrida, mesmoanossamaisaparentemente imediata experiência não é uma reflexão direta do mundo exterior mas um contato feito com aquilo que já está inscrito, inconscientemente, na memória... E, assim como [ocorre] coma presença, assim também [ocorre] como presente temporal. Nós jamais poderemos emparelhar com o momento exato denosso contato sensorial como mundo exterior, estaremoschegando atrasados sempre para o 'agora' de nossa própria experiência. ... O conceito fenomenológico do momento presente absoluto, juntamente com o conceito fenomenológico 'das coisas em si mesmo', é desconstruído como uma ilusão pela teoria geral da Escrita de Derrida." (Harland 1987: 144, ênfase minha)
\end{abstract}

Aspostulações deDerrida, informadas, entre outras, pelas teorias de Freud e Lacan, parecem estar também amparadas por experimentosmédicosrealizadoscomsujeitoshipnotizados. Esses pacientes são capazes de lembrar não apenas suas experiências passadas, por maisantigas quesejam, mastambém sentimentoseemoçõesqueforam reprimidos emantidosfora da consciência por ocasião de sua ocorrência; e, o queéainda mais interessante, esses sujeitos podem recuperar experiências que, embora não exatamente repri- midas, não foram significativas o bastante para serem selecionadas para a consciência no momento dasocorrências. Temsido mesmo sugerido que o inconsciente da mente mantém umarquivo deabsol utamentetudo queo sujeito viveu, nos seus mínimos pormenores (Harland 1987: 145).

A tualmente se acredita que a hipnose funciona primariamente graças à sugestão verbal; equeexisteumcontínuo entreotranse hipnótico ea sugestão verbal dada ao sujeito acordado. Isso pareceindicar que, real mente, o inconsciente responde à 'linguagem'. Mais que isso, o hipnotista pode induzir sujeitos à alucinações, distorcendo suas percepções sensoriais e mesmo as recordações a respeito quando acordado (Harland 1987: 35). Parece então que tudo aquilo em que acreditamos resulta de sugestões passadas que nos foram dadas por terceiros - o sujeito presente seria portanto o resultado de um somatório de persuasões passadas.

O traço na mente, no inconsciente, também se manifesta nos sonhos, onde as imagens são investidas com fortes sentimentos que não derivam diretamente de seus atributosracionaisou 'objetivos', comonotou Freud ao escrever sobre os deslocamentos e condensações que ocorrem no trabalho do sonho. Escreve Harland:

“... em nossos sonhos freqüentemente nosdamosconta quealguémfez algo ou disse algo mesmo que [no sonho] não tenhamos visto o quefoi feito ou escutado o que foi dito. Ou parece que possuimos 'lembranças' que não resultam de nossa experiência presente no sonho, e que nunca podem ser lembradas em imagens da experiência presente. Tais 'memórias' se ajustam bem à descrição deDerrida de 'um "passado" que jamais foi nem nunca jamais será presente'." (Harland 1987: 144)

Quando experimentamos nossos sonhos, o fazemos principalmente através de esforços conscientes subsequentes de interpretação eemtermosdepós-efeitos, pois 
oinconscientediferencia-se(afasta-se) edifere (atrasa-se), e assim os traços dos traços inconscientes não podem jamais ser recuperados:

“A alteridadedo 'inconsciente' nostorna preocupados não com horizontes de presentes- passados ou futuros- modificados, mas com um 'passado' que jamais esteve presente, eque jamais estará, cujo futurovindouro nuncaseráuma produção ou uma reprodução na forma depresença. Portanto, o conceito detraço éincompatível com o conceito de retenção, do tornar-se passado daquilo que foi presente. Não sepodepensar o traço - e portanto, différance - com base no presente, ou na presença do presente." (Derrida 1972/ 1982: 21)

O inconsciente, Freud e Lacan nos ensinaram, éo responsável por nossosatosfal hos, orais ou escritos, nossas neuroses, fixações, desvios, ansiedades, agressividade. Ele também parece ser o responsável pelos efeitos do que se convencionou chamar de 'propaganda subliminar', assim como por todas as demais formas de comportamentos ilógicosou 'irracionais', violências, psicoses, traumas, compulsões, desejos, etc.

Harland (1987) nos oferece a sua versão da gramatologia de Derrida, que poderá ser bastante útil para entender as premissas e 'origens' daquela teoria, da seguinte forma:

“Derrida deriva sua teoria da 'arqueescrita' a partir deFreud, especialmente do ensaio de Freud entitulado 'N ota sobreo TabletedeEscritaMágico' ['N ote on the Mystic Writing Pad']. N este ensaio, Freud compara o aparato psíquico ao Tablete de Escrita Místico (ou Mágico), queaindahojeévendido como uma brinquedo novidade para crianças. $\mathrm{O}$ tableteéfeito deumafolhatransparente de celulóide que recobre uma folha de papel não-absorvente que por sua vez recobreumabaseencerada. Umestilete, ao pressionar o celulóide, pressiona o papel contra a base encerada, e esse último contato faz com quea cor escura da base transpareça como uma escrita no papel levemente colorido de cima. Tal escrita não está real mente depositada no papel, epodeser feita desaparecer simplesmente levantando e separando o papel da base. Contudo, como observou Freud, a baseencerada ainda retém a marca inscrita pelo estilete, mesmo quando o escritojánão seja mais visível. N esse aspecto, a base pode ser comparada ao inconsciente da mente, que retém o queelenão percebe, eo papel (eo celulóide) pode ser comparado ao sistema de consciência-percepção, que por sua vez transmite [e conscientiza] aquilo que não retém.

Derridatira o máximo possível dessa analogia quando ele interpreta o papel do Bahnung ('facilitação') e do Spur ('o traço) no modelo genérico deFreud para a percepção e a memória. N aquele modelo deFreud, uma força qual quer excitadanoscircuitos perceptuaisdoindivíduo, passa através do sistema neurológico do cérebro, abrindo ou facilitando um caminho ou traço de baixa resistênciael etroquímica. Estecaminho ou traço então permanececomo a forma física de uma memória inconsciente, o canal entalhado ao longo do qual forças futuras poderão mais facilmente fluir e seguir. Derrida aceita essa teoria do traço, ea combina com a escrita inscrita sobre a base encerada do Tablete de Escrita Místico (ou Mágico). Pois tal escritatambémtemaforma deumcanal entalhado, escavado pela pressão do estilete. Pelainterpretação deDerrida, 0 traço éportanto um signo [material ], da mesma maneiraqueaescritaéumsigno [material]." (Harland 1987: 142-43)

Derrida, adicionalmente, assume quea operação de levantar e descolar o papel de suabaseécontínua, oquemantémtodaaquela escrita mental sob constante apagamento (Derrida 1967/ 1978: 226). A legibilidade da 
escrita que aparece na superfície do tablete, nota ele, é produzida indiretamente e é um efeito posterior da pressão do estilete. De maneirasimilar, nossas experiênciassó vemà tona em nossa consciência após um certo tempo, depois da ocorrência do evento queas originaram: "ParaDerrida, mesmo nossamais aparentemente imediata experiência não é uma reflexão direta do mundo exterior mas um contato feito com aquilo que já tinha sido lá inscrito, inconscientemente, na memória", interpreta Harland (1987: 144). Em outras palavras, toda significação depende do estabelecimento de relações, dos sinais sensórios quechegam com traçosmnemônicos (históricos) de sinais previamente processados, assim como com traços de associações anteriores entre eles, para fins de comparação e correlação. Pelo mesmo raciocínio, então, se nossa memória inconscientenão participasse prioritariamente de todos nossos atos e percepções, não seria possível existir nenhuma escrita legível (consciente) posterior.

As postulações de Derrida, somadas às antigasespeculaçõesdePeirce, desestabilizam tradicionais convicções sobre a existência de uma realidade positiva, essencial, nãomediatizada (ou seja, de um mundo designificados fixos e estáveis), assim como abalam crenças cartesianas sobrea intei reza do 'indivíduo' e sua absoluta racionalidade, pois se baseiam em mitos que derivam da metafísica da presença, com raízes profundas na filosofia ocidental, desde a Grécia antiga. Noções positivistas e racional istas sobre o homem e sua realidade não se sustentam mais, pois estão apoiadas, em última análise, na crença da maioria dos filósofos de que a voz seja o mais antigo eúnico verdadeiro 'instrumento' de comunicação do pensamento (como se só existisse uma única forma de linguagem, a verbal, ecomo seessafossedenaturezadiversa do pensar). E as intenções conscientes do sujeito não podem maisgarantir a precisão de suas falas ou a significação de seus signos.

Para Derrida e seus seguidores pósestruturalistas, não existe nenhum significado que possa ser considerado o mais transcendente, o derradeiro, ou o mais verdadei ro dentre todos; é ilusório acreditar na existência decentros ou origens transcendentais que possam ancorar o processo designificação ou uma pseudo ‘natureza humana' ou 'essência última', seja divina, seja material. Tudo o que existe é energia em constante movimento, e tudo o que percebemos dessa realidade está submetido ao efeito da différance, da arqueescrita. Como assinala Harland, para Derrida "a consciência (no seu sentido usual) é uma ilusão queosseres humanos inventaram porque sempre temeram as consequências de uma concepção materialista da mente . . . que mesmo ainda hoje não vão além das antigas noções de alma e espírito" (Harland 1987: 146, ênfase minha).

Então, segundo as postulações de Derrida, a arque-escrita, o pro-grama, éa précondição necessária para o pensar ou significar. Tanto a fala como a escrita gráfica são ambas manifestações secundárias, efeitos de uma escrita mental anterior, da différance, e que não pode ser acessada nem controlada pelo sujeito. Portanto, todas as manifestações semióticas do sujeito dependem dessa arqueescrita e tem o mesmo status e interdependênciaem relaçãoàsignificação: gestos, mímica, dança, escultura, música, fotografia, filme, escrita gráfica, fala, etc. são todos 'escritas', com especificidades, limitações e potencialidades diversas, mas todos igualmente interrelacionados, heterogêneos, produzidos pela, e sujeitos à, différance:

“D ifférance, a ausência irredutível de intenção [consciência] . . . é o que me autoriza . . . a postular a estrutura grafemática geral de toda 'comunicação'." (Derrida 1972/ 1982: 327)

Portanto, a fala não podeser pressuposta como sendo 'o referente' que origina 'a sombra' da escrita gráfica, pois a própria fala já seria uma sombra derivada de uma ação anterior de significação, da qual ela manifestaria o traço, da qual ela seria apenas um indicador, eassim por diante para as demais manifestações, numa regressão infinita (Hawkes 1977: 148). Toda e qualquer repre- 
sentação da realidade, seja de que natureza for, está tão distanciada do 'real' quanto as demais - nenhuma é auto-suficiente ou mais verdadeira que as demais, todas são igualmente imprecisas, ambíguas e diferentes em relação aquilo a que se referem. O 'real' é o impossível, alertava Lacan, seguindo os pensamentos de Peirce e Saussure, pois el e está sempresendo mediado por signos, não pode ser apreendido diretamente pel o nosso cérebro; ou, nas palavras de Derrida, "não existe a experiência da presença pura, mas apenas correntes de marcas diferenciais" (Derrida 1972/ 1982: 318).

Maisainda, Derridapostulaque, sepode ser dito que nenhum significante é capaz de produzir apenas um único efeito de significado ou de referência, o contexto também não poderá ser nunca absolutamente determinável de modo a ser invocado como garantia de um sentido inequívoco para qualquer signo.

Porque, primeiramente, a ausência do referente constrói a marca; e a eventual presença do referente no momento quando ele é designado não muda nada acerca da estrutura da marca - de maneira que ela pode, ela deveser capaz defuncionar sem um original ou referente própriamente dito, ela deve ser iterável, repetível, de outra maneira não haveria a possibilidade de existirem nem textos nem comunicação (Derrida 1972/ 1982: 318). Basta lembrar aqui, por exemplo, o pronome 'eu'.

Em segundo lugar, porque podemos manipular signossem qual quer intenção conscientedesignificação, damesmamaneiraque podemos produzir textos sem significados objetivos (tal como 'círculo quadrado'), ou textos agramaticais (tal como 'verdeéou'); e, mesmo assim, eles produzem efeitos-de-sentido('círculoquadrado' poderásignificar uma proposição falsa ou contraditória, enquanto 'verdeéou' poderá ser um exemplo deincoerência, como observaDerrida(1972/ 1982: 31820).

Em terceiro lugar, o significado é instável porquequalquer signo, lingüístico ou não, falado, escrito ou de outra forma qualquer, não importa se articulado através de uma unidade sintática grande ou pequena, pode ser citado, posto entre aspas, implantado em outros textos (aintertextual ização dequefala Kristeva): "dessa maneira ele pode romper com qualquer contexto dado ['apropriado' ou 'original'], e engendrar infinitos novos contextosdeumamaneiraabsolutamentenãosaturável" (Derrida 1972/ 1982: 320). Isto é, todos os signos aparecem em contextos específicos, dosquaisdependemosparainterpretáIos, mas contexto nenhum pode conter, ou ancorar, ou impedir um signo de produzir sempre novos sentidos para o sujeito. Pois textosestão sempreengendrandonovostextos einterpretações, esignificantes estão sempre sendo associados com outros significantes.

Esta possibilidade de citação, duplicação, repetição, 'duplicidade', esta 'iterabilidadeda marca', esta absoluta autonomia do significante, não é um acidente ou anomalia, mas uma necessidade estrutural "sem a qual uma marca [ou um sujeito, quetambéméum signo] não mais poderia ter um funcionamento dito 'normal'. Pois o que seria de uma marca que ninguém pudesse citar? E cuja origem não pudesse ser perdida ao longo do caminho?" (Derrida 1972/ 1982: 320-21). Esta noção também informa o conceito de intertextualidade proposto por Kristeva- para ela todos os textos são formados por um entrelaçar decitações oriundas deoutros textos passados, que por sua vez provêm de textos anteriores, e assim por diante. $\mathrm{Ne}$ nhumtexto éjamais um texto completamente 'original', mas sim uma citação e uma transformação, ou mutação, detextos quelheprecederam.

Portanto, argumenta Derrida, escrever ou produzir uma marca é constituir uma máquinaquesetorna produtivadali emdiante, uma vez queela é "separada no nascimento da assistência de seu pai", o autor, e essa desaparição não Ihe impedirá de funcionar e deentregar edeentregar-se, à releitura eàreescrita" (Derrida 1972/ 1982: 320). O signo não apenas gera polissemia, múltiplas interpretações, mas, mais queisso, el ecausa disseminação, um termo queDerrida costuma usar 
com freqüência para enfatizar o movimento perpétuo de significantes significando, sempre desdobrando-se em novos significados, sem que jamais possamos seguir-lhes as pegadas até a sua 'origem' hipotética. Como observa Harland (1987):

"A linguagem no modo de disseminação [isto é, entendida como uma produção de sentidos] está em um desbalanceamento infindável efora deequilíbrio . . . Ou, para cunhar uma metáfora elétrica: enquantoa'língua' deSaussure existe meramente em termos de diferenciais estáticos devoltagem entre polos positivos e negativos, a linguagem como disseminação existe em termos decorrentesquefluem depóloa pólo (a pólo a pólo), criando eanulando diferenças de voltagem. . . . [Portanto] Derrida reabre a dimensão do tempo que os estruturalistas haviam excluído de seus modelos espaciais..." (Harland 1987: 137, ênfase minha)

Por influência, talvez, da semiótica de Peirce, que Derrida não desconhece?

Então, a teoria da différance (para nos fixarmos neste termo) de Derrida desafia a noção metafísicatradicional dosigno binário, monosêmico, fechado, imutável, assim como os model os estruturalistas que postulam linguagem e comunicação funcionando como códigos estáveis, por (re)introduzir nesses conceitos os efeitos das variáveis tempo e subjetividade, para dar conta de diferenças individuais no ler/ escrever de textos. O sentido, a significação, portanto, são vistos como efeitos dos significantes que se obtém de um texto, num certo contexto, eatravés das correlações queel es estabelecem comoutrostextos esignificantes previamentegravados na memória dos sujeitos. Sendo o resultado de interpretações subjetivas, condicionadas históricamente, o sentido está sempre mudando. Com isso, é impossível que alguém possa ter a pretensão de estabelecer o ‘verdadeiro' significado de qualquer texto ou as 'verdadeiras' intenções do seu autor - nem mesmo o próprio tem esse direito. Assim como também fica impossibilitada a medida da'eficiência' dequal quer comunicação. Tudo o quea significação nos permitefazer, parece sugerir Derrida, éjogar com probabilidadese hipóteses, arriscando suposições fundamentadas e correndo riscos cal culados.

\section{Bibliografia}

COWARD, R, and ELLIS, I (1977) Language and M aterialism: Developments in Semiology and the Theory of the Subject, London: Routledge \& Kegan Paul

DERRIDA, J (1967/ 1976) of Grammatology, translated by Gayatri Spivak, Baltimore, Maryland: The John Hopkins University Press (First published in 1967 as D ela Grammatologie, Paris: Les Éditions de Minuit)

DERRIDA, J (1967/ 1978) Writing and Difference, translated by Alan Bass, London: Routledge\& Kegan Paul

DERRIDA, J (1972/ 1982) Margins of Philosophy, translated by Alan Bass, Chicago: Chicago University Press

HARLAND, R (1987) Superstructuralism, New Accents, ed.T Hawkes, London: Methuen

HAWKES, T (1977) Structuralism and Semiotics, New Accents, ed.T Hawkes, London: Methuen

JEFFERSON, A (1986) 'Structuralism and Post-Structuralism', in Modern Literary Theory: A Comparative Introduction, edited by Ann Jefferson and David Robey, 2nd edition, London: B T Batfford Ltd, 92-121

LACAN, J (1966/ 1977) Écrits: A Selection, translated by Alan Sheridan, London: Tavistock Publications (A selection from Écrits originally published in 1966, Paris: Éditions du Seuil)

LACAN, J (1972) 'Theinsistence of theletter in theunconscious', in The Structuralists: From M arx to Lévis Strauss, ed. by Richel and Fernando de George, New York: Doubleday Anchor

LACAN, J (1973/ 1979) The Four Fundamental Concepts of Psychoanalysis, edited by Jacques-Alain Miller, translated by 
Alan Sheridan, Harmondsworth: Penguin (First published in 1973 as Le Séminaire de Jacques Lacan, Livre XI, 'Les quatre concepts fondamentaux de la psychanalyse', Paris: Éditions du Seuil)

NORRIS, C (1987) Derrida, Fontana Modern Masters, ed. by Frank Kermode, London: Fontana Press

PEIRCE, C S (1940/ 1955) Philosophical Writings of Peirce, selected and edited with an introduction by Justus Buchler, New York: Dover Publications (First published in 1940 as The Philosophy of Peirce: Selected Writings, ed. by Justus Buchler, London: Routledge \& Kegan Paul) 